\title{
EKSPLORASI DAN INDENTIFIKASI JENIS-JENIS ANGGREK DI KAWASAN HUTAN PULAU MANSINAM KABUPATEN MANOKWARI
}

\section{(Exploration and Identification of Orchid Species Around Mansinam Island Forest of Manokwari)}

\author{
NIKSON REZALL BIETH ${ }^{1}$, AGUSTINA Y.S. AROBAYA ${ }^{1 凶}$ \\ Program Studi Konservasi Sumberdaya Hutan, Fakultas Kehutanan Universitas Papua Manokwari, \\ Papua Barat, 98314. Tlp/Fax: +62986211065. \\ $\triangle$ Penulis Korespondensi: Email: agustinaarobaya@yahoo.com \\ Diterima: 04 Apr 2020| Disetujui:16 Mei 2020
}

\begin{abstract}
Abstrak. Penelitian ini bertujuan untuk mengetahui keberadaan anggrek epifit dengan menggunakan metode survey dengan pembuatan jalur per plot pengamatan jenis anggrek. Parameter yang dilihat meliputi karakter morfologi anggrek epifit (perawakan, akar, batang, daun, buah dan bunga) dan habitat tempat tumbuh. Dari hasil penelitian teridentifikasi 6 jenis anggrek epifit yang terdiri dari yaitu: Dendrobium bifalce Lindl, Dendrobium mirbelianum Gaudich, Dendrobium schulleri J.J.Sm, Grammatophylum scriptum (Lindl.) Blume, Grammatophylum speciosum Blume, dan Pomatocalpa sp aff. Marsupial. Jenis - jenis pohon inang yang di tumbuhi jenis anggrek epifit ini antara lain Mangifera indica, Alstonia scholaris, Baringtonia asicatica, Pometia sp, dan Terminalia catappa yang pertumbuhannya didominasi pada batang dan cabang pohon inang.
\end{abstract}

Kata kunci: anggrek, epifit, perawakan, tanaman inang, hutan dataran rendah

Abstract. This study was focusing on identifying types of epiphytic orchid species through field survey by establishing plots and tracks for observation. The main parameter in the study was morphological characteristic of epiphytic orchid that covers shape, root, stem, leaf, fruit, and flower as well as its growing habitat. From the result standpoint, 6 epiphytic orchid species were identified that consisted of Dendrobium bifalce Lindl, Dendrobium mirbelianum Gaudich, Dendrobium schulleri J.J.Sm, Grammatophylum scriptum (Lindl.) Blume, Grammatophylum speciosum Blume, and Pomatocalpa sp aff Marsupial. In addition to their hosted plant, the result found several species of plant such as Mangifera indica, Alstonia scholaris, Baringtonia asicatica, Pometia sp, and Terminalia catappa which their growth was mostly sticking to the main stem and branch.

Keywords: orchid, epiphyte, shape, hosted plant, lowland forest

\section{PENDAHULUAN}

Hutan sudah diketahui sebagai salah satu sumber daya alam yang dapat diperbaharui dan banyak memiliki manfaat bagi kelangsungan hidup manusia. Fungsi hutan antara lain sebagai pelindung ekosistem, pengasil devisa, peningkatan kesejatraan rakyat (Arif 1994). Hutan Papua mengandung sumber daya alam yang sangat melimpah dengan keanekaragaman hayati flora dan fauna yang belum terungkap secara optimal, salah satu sumber daya hayati Papua adalah kekayaan jenis flora yang cukup potensial dan tersebar mulai dari daerah pesisir pantai hingga dataran tinggi dan Pegunungan (Petocz 1987; Bratawinata 2001; Lekitoo et al. 2017). Keragaman jenis flora ini bervairasi dari jenis, ukuran, bentuk, dan warna yang beradaptasi dengan tempat tumbuhnya. Sumber 
daya hayati yang tumbuh di wilayah pesisir dan kepulauan ini dapat dijumpai di salah satu pulau yang terletak pada kabupaten Manokwari provinsi Papua Barat, yang juga merupakan situs bersejarah bagi umat Kristen di tanah Papua yaitu Pulau Mansinam.

Kawasan hutan alam Pulau Mansinam, kabupaten Manokwari merupakan habitat yang cocok bagi beberapa jenis fauna dan tumbuhan (Abaire dan Worabai 2018). Fauna atau satwa liar yang menghuni pulau ini antara lain jenis Soa-soa (Varanus sp.), kelelawar, dan beberapa jenis burung seperti Cacatua (Galerita triton). Jenis flora yang dapat dijumpai tumbuh secara alami di pulau ini antara lain Coconut nucifera (kelapa), Intsia bijuga (kayu besi), Elaeocarpus sp, Terminalia catappa (ketapang), Premna corymbosa, Ficus nadosa (buah roda), jenis epifit seperti Pothos sp., dan anggrek. Jenis anggrek yang sering dijumpai tumbuh secara epifit pada inang (host plant).

Anggrek termasuk famili Orchidaceae dikenal karena keunikan bentuk bunga warna dan aromanya. Kekayaan alam ini telah menarik para ahli botani untuk mengeksplorasi dan meneliti, selain itu juga memicu para pemburu bunga hias untuk mengeksploitasi dari habitat alami untuk kepentingan ekonomi dan hobi.

Diketahui jumlah anggrek secara keseluruhan sekitar 25.000 jenis tergolong dalam 800 marga. Indonesia memiliki kurang lebih 6000 jenis anggrek yang tersebar mulai dari bagian Barat Sabang sampai ke wilayah timur Merauke dan dari Utara Sangihe Talaud di Pulau Miangas sampai ke bagian paling Selatan Nusa Tenggara Timur di Pulau Rote (Soetopo 2009). Adapun tujuan dari studi ini yaitu untuk mengidentifikasi jenis - jenis anggek, mendokumentasi distribusi jenis anggrek, dan untuk mengidentifikasi jenis pohon inang yang ditumbuhi oleh jenis anggrek yang terdapat di Pulau Mansinam.

\section{METODOLOGI PENELITIAN}

Penelitian ini dimulai pada tanggal $6 \mathrm{~s} / \mathrm{d} 9$ Mei tahun 2015 yang terletak di pulau Mansinam kabupaten Manokwari provinsi Papua Barat dengan beberapa kelengkapan alat dan bahan seperti kamera, meter roll, mistar, parang, gunting stek, label spesimen, alat tulis menulis serta bahan yang di gunakan adalah alkohol $70 \%$ dan plastik specimen.

\section{Metode Penelitian}

Penelitian ini dimulai dengan survei dan pembuatan jalur utama, pada setiap jalur dibuat 3 plot pengamatan, jarak antar plot adalah dengan luasan plot $25 \times 25$ meter, jenis- jenis anggrek yang ditemukan di setiap plot pada jalur dicatat, demikian juga dengan jenis inang tempat tumbuhnya (Soerianegara dan Indrawan 1976).

\section{Variabel Pengamatan}

Variabel yang digunakan dalam penelitian ini yaitu variabel yang meliputi : jenis-jenis anggrek, penyebaran jenis anggrek di Pulau Mansinam, sedangkan variabel lainnya meliputi, asosiasi dengan habitat anggrek atau tempat tumbuh.

\section{Pengumpulan Data}

Data yang di kumpulkan di lapangan meliputi data primer dan data sekunder.

Data primer: data yang di kumpulkan meliputi jenis-jenis anggrek, jumlah penyebaran anggrek, dan jenis pohon inang di peroleh dengan mencatat langsung di lapangan. Data sekunder: data meliputi keadaan umum lokasi penelitian yaitu data penduduk dan data yang di peroleh dari instasi terkait.

\section{Analisis Data}

Data yang di peroleh dari hasil penelitian ini akan di analisis secara deskritif dan di sajikan dalam bentuk tabel dan gambar. 


\section{HASIL DAN PEMBAHASAN}

Berdasarkan hasil penelitian yang di lakukan pada kawasan hutan Pulau Mansinam berhasil di jumpai 6 jenis anggrek epifit yang terdiri yaitu : Dendrobium bifalce Lindl, Dendrobium mirbelianum Gaudich, Dendrobium schulleri J.J.Sm, Grammatophylum scriptum (Lindl.)Blume, Grammatophylum speciosum Blume, Pomatocalpa sp. aff. marsupiale.

Tabel 1. Jenis - jenis epifit/anggrek, famili dan bentuk hidup dan jenis pohon inang

\begin{tabular}{|c|c|c|c|c|}
\hline No. & Nama jenis & Famili & Habitat & Jenis pohon inang \\
\hline 1. & Dendrobium bifalce Lindl. & Orchidaceae & Epifit & Terminalia catappa \\
\hline 2. & $\begin{array}{l}\text { Dendrobium mirbelianum } \\
\text { Gaudich }\end{array}$ & Orchidaceae & Epifit & $\begin{array}{l}\text { Pohon mati (sulit } \\
\text { identifikasi) }\end{array}$ \\
\hline 3. & Dendrobium schulleri J.J.Sm & Orchidaceae & Epifit & Terminalia catappa \\
\hline 4. & $\begin{array}{l}\text { Grammatophyllum scriptum } \\
\text { (Lindl.) Blume }\end{array}$ & Orchidaceae & Epifit & Mangifera indica \\
\hline 5. & $\begin{array}{l}\text { Grammatophyllum } \\
\text { Speciosum Blume }\end{array}$ & Orchidaceae & Epifit & $\begin{array}{l}\text { Pohon mati (sulit } \\
\text { identifikasi) }\end{array}$ \\
\hline 6. & $\begin{array}{l}\text { Pomatocalpa sp. Aff. } \\
\text { Marsupiale }\end{array}$ & Orchidaceae & Epifit & $\begin{array}{l}\text { Pohon mati (sulit } \\
\text { identifikasi) }\end{array}$ \\
\hline
\end{tabular}

Tabel 1 terlihat anggrek/epifit yang banyak di temukan di kawasan hutan Pulau Mansinam famili Orchidaceae dan genus Dendrobium. sedangkan pohon inang yang di tumbuhi anggrek epifit adalah Alstonia scholaris, Mangifera indica, dan Terminalia catapa. Selain itu, jenis pohon-pohon tersebut di tumbuhi oleh anggrek epifit karena sangat dipengaruhi oleh karakter morfologinya, terutama tektur kulit yang kasar sehingga anggrek epifit dapat menempel akarnya pada batang tersebut.

\section{Deskripsi karakteristik Morfologi Jenis- Jenis Anggrek Epifit}

\section{Dendrobium bifalce Lindl. (Gambar 1)}

Perawakan : Anggrek berukuran sedang, tumbuh tegak

Akar : Serabut, warna putih kecoklatan tidak berambut, panjang akar antara $20-25 \mathrm{~cm}$, berwarna putih kecoklatan.

Batang : Tipe pertumbuhan batang bunga 80 $\mathrm{cm}$, dan lebar batang $4 \mathrm{~cm}$
Daun : Warna hijau keputian, lebar daun $7 \mathrm{~cm}$, panjang daun $45 \mathrm{~cm}$, ujung daun (meruncing) jumlah daun 6

Buah dan Bunga : Tidak di temukan saat pengamatan

Habitat : Hidup menempel di bagian cabang Terminalia catappa, pada ketinggian $1 \mathrm{~m}$ dari permukaan tanah.

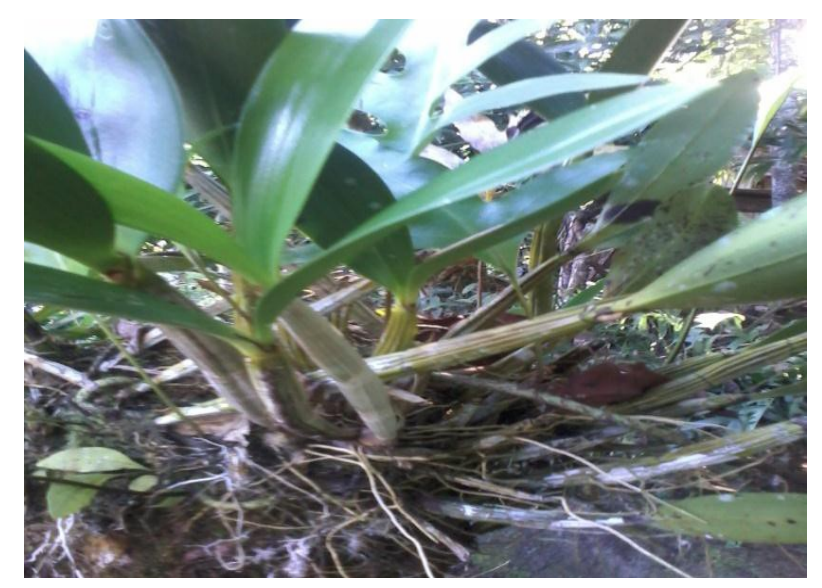

Gambar 1. Dendrobium bifalce Lindl. Foto. Echon Bieth 
Dendrobium mirbelianum Gaudich (Gambar 2) Perawakan : Anggrek berukuran sedang, tumbuh tegak ke atas

Akar : Serabut, warna putih, tidak berambut

Batang : Tipe pertumbuhan batang bunga 45 $\mathrm{cm}$, jumlah batang 3 , lebar batang $1,5 \mathrm{~cm}$, panjang batang $30 \mathrm{~cm}$

Daun :Warna hijau bintik putih, lebar daun 4 $\mathrm{cm}$, panjang daun $24 \mathrm{~cm}$, jumlah daun 6

Bunga dan Buah : Tidak di temukan saat pengamatan

Habitat : Hidup menempel pada pohon mati, sulit di identifikasi pada ketinggian $15 \mathrm{~cm}$ dari tanah.

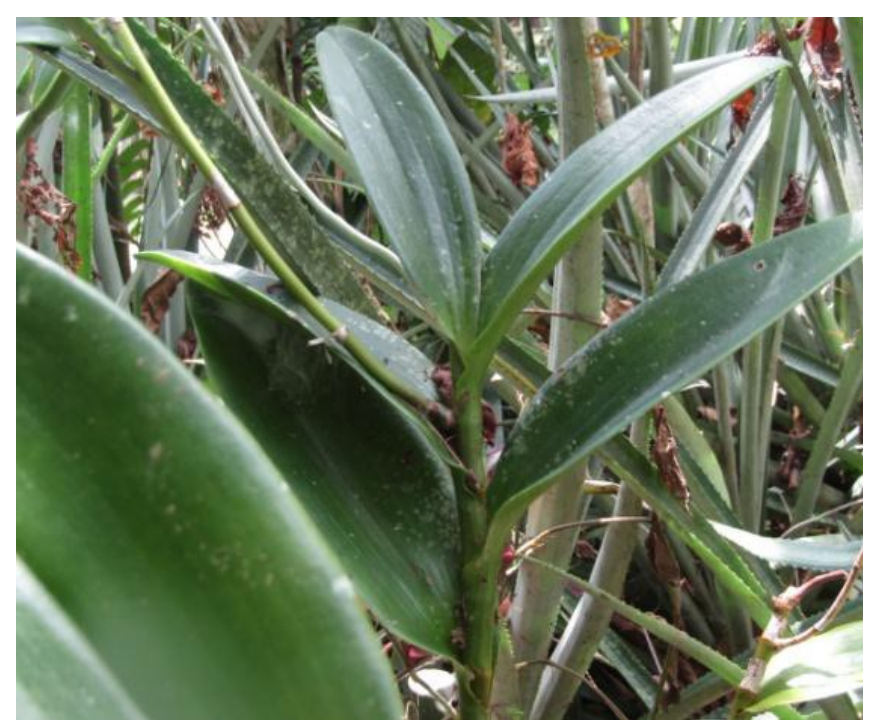

Gambar 2. Dendrobium mirbelianum Gaudich. Foto. Echon bieth

\section{Dendrobium schulleri J.J.Sm. (Gambar 3)}

Perawakan : Anggrek epifit berukuran besar, tumbuh anggrek tegak ke atas.

Akar : Serabut, warna putih kecoklatan tidak berambut, panjang akar antara 20-25 cm, berwarna putih kecokltan.

Batang : Tipe pertumbuhan batang menjalar ke atas.

Daun : Warna hijau keputian, lebar daun $8 \mathrm{~cm}$, panjang daun $18 \mathrm{~cm}$, ujung daun (meruncing) jumlah daun 23.
Buah dan Bunga : Tidak di temukan saat pengamatan.

Habitat : Hidup menempel di bagian cabang Terminalia catappa pada ketinggian 5 meter dari permukaan tanah.

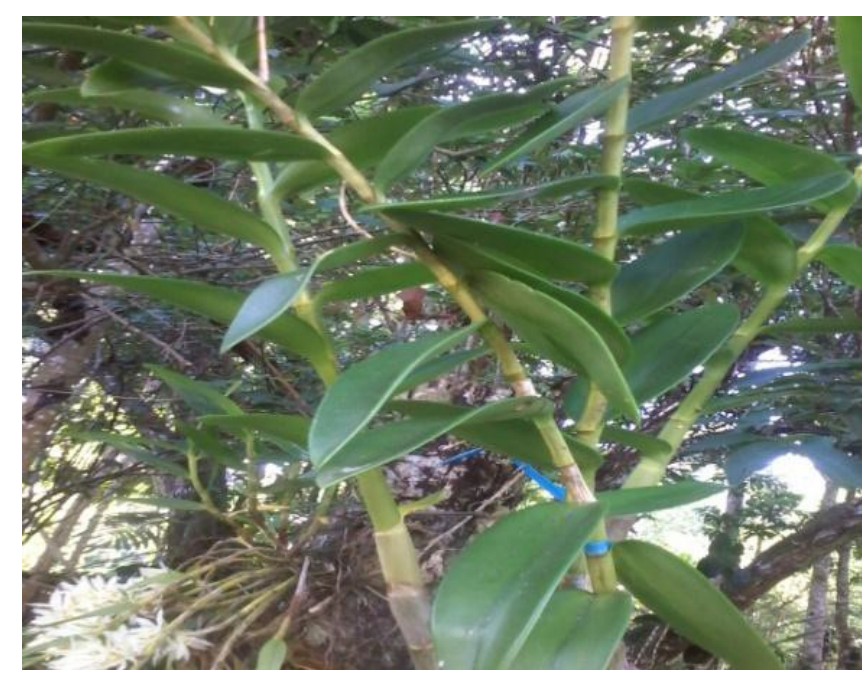

Gambar 3. Dendrobium schulleri J.J.Sm. Foto. Echon Bieth

Grammatophyllum scriptum (Lindl.) Blume

(Gambar 4)

Perawakan : Anggrek berukuran sedang, tumbuh tegak berumpun ke atas

Akar : Serabut, warna akar putih kecoklatan, berambut.

Batang : Bulat, lebar batang 3,5 cm, panjang batang bunga $60 \mathrm{~cm}$.

Daun : Panjang daun $40 \mathrm{~cm}$, lebar daun $4,5 \mathrm{~cm}$, jumlah daun 3

Bunga dan Buah : Tidak di temukan saat pengamatan

Habitat : Hidup menempel pada pohon mangifera indica pada ketinggian $1 \mathrm{~m}$ dari tanah.

Gambar 4. 


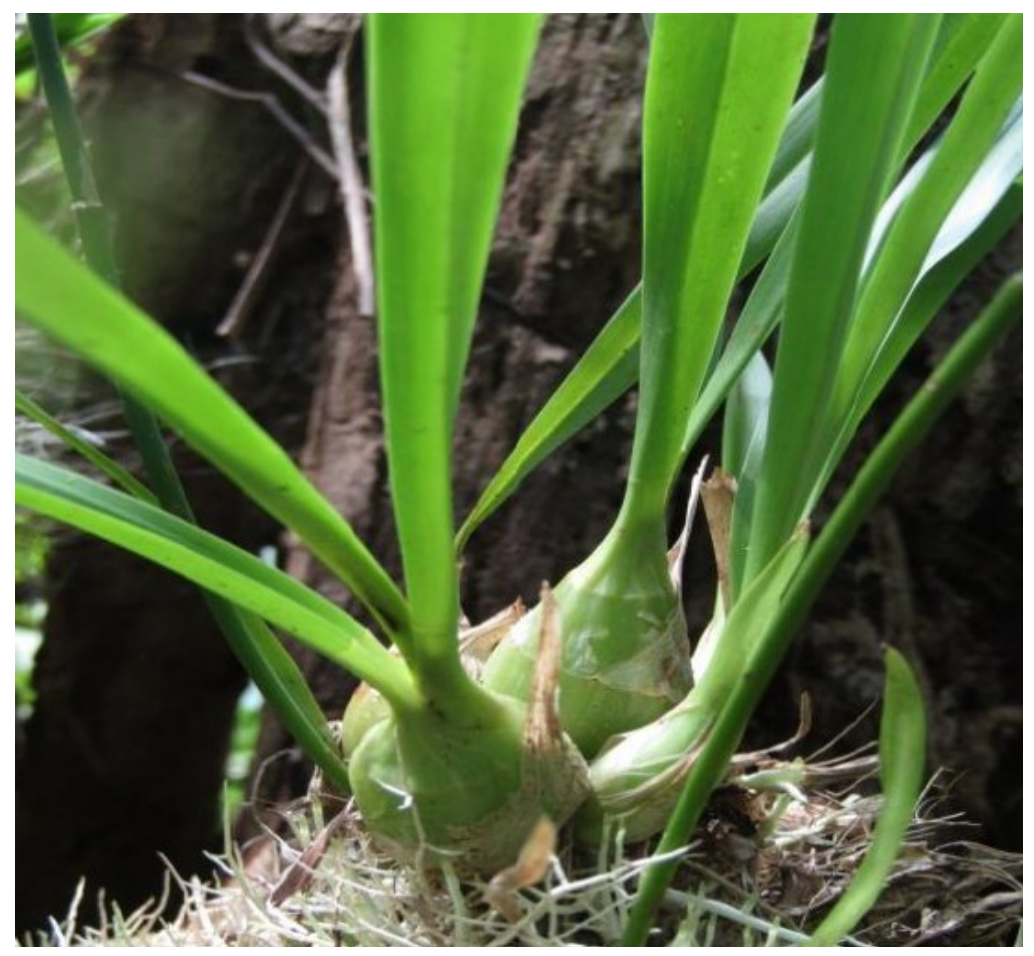

Gambar 4. Grammatophylum scriptum (Lindl.)Blume Foto. Echon Bieth

\section{Grammatophyllum speciosum Blume} (Gambar 5)

Perawakan : Anggrek berukuran besar, tumbuh berumpun tegak ke atas pada setiap batang.

Akar : Serabut berambut, warna akar putih kecoklatan.

Batang : Tipe pertumbuhan batang warna hijau bercak kehitaman panjang batang $50-70 \mathrm{~cm}$, lebar batang $3,5 \mathrm{~cm}$, jumlah batang 11 .

Daun : Pita talang, panjang daun 39-60 cm, lebar daun $3 \mathrm{~cm}$ bentuk daun panjang meruncing dan memiliki tulang daun, letak daun sejajar

Bunga dan Buah : Tidak di temukan saat pengamatan.

Habitat : Tumbuh pada batang pohon, sulit di identifikasi pada ketinggian $60 \mathrm{~cm}$ di permukaan tanah.

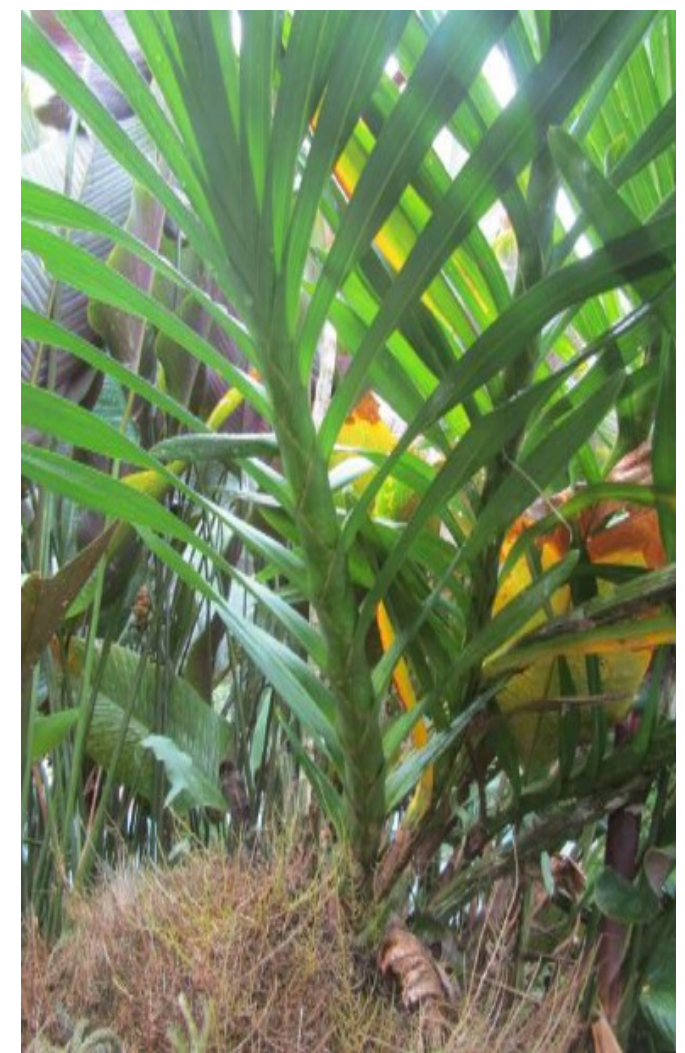

Gambar 5. Grammatophylum

speciosum Blume Foto.Echon bieth

Pomatocalpa sp. aff. marsupiale (Kraenzl.) J.J.Sm. (Gambar 6)

Perawakan : Anggrek berukuran sedang, tumbuh tegak dan tidak berumpun

Akar : Serabut, tidak berambut, panjang akar antara 20-29 cm, berwarna putih kecoklatan.

Batang : Tipe pertumbuhan batang monopodial, bentuk batang selindris, tektur halus, warna hijau, panjang batang antara 17.6 - 20.5 , diameter antara $1,2-1,8 \mathrm{~cm}$ jumlah batang antara 1-12

Daun : Pita talang (linier), panjang antara 20$23 \mathrm{~cm}$, lebar antara $4-5 \mathrm{~cm}$, tepi daun rata (entire), warna hijau, pangkal membulat, ujung daun membulat (acuminat), pertulangan sejajar tepi daun, jumlah daun perbatang antara 10-13, letak daun berhadapan. 


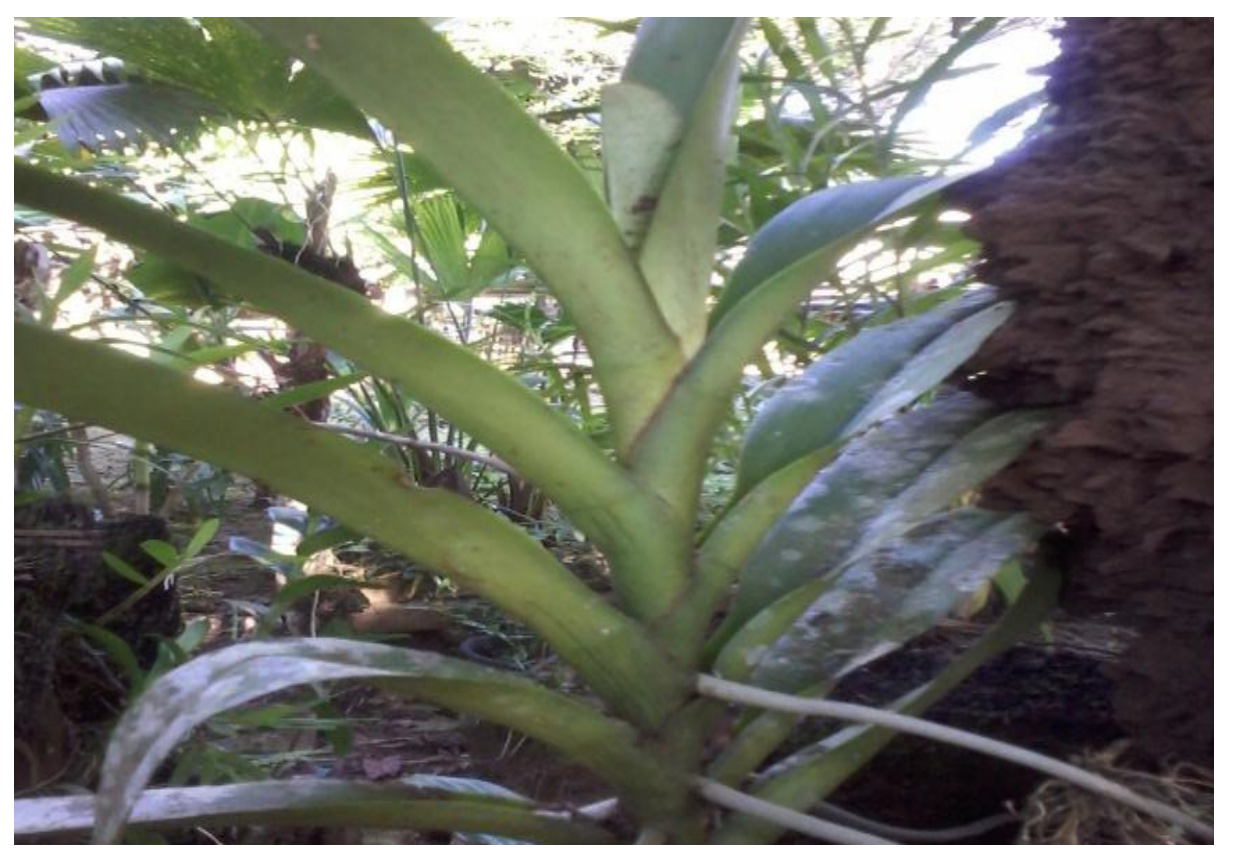

tersebut dengan tanpa memperhatikan keberadaan dan kelestariannya (Mooy 2005).

Faktor lain yang menyebabkan berkurang populasi beberapa spesies anggrek epifit yang ada di Pulau Mansinam adalah perubahan kawasan hutan menjadi ladang atau kebun dan adanya pengambilan hasil hutan berupa kayu untuk kayu bakar atau bahan bangunan yang secara langsung merusak habitat dari anggrek ini. Kondisi ini akan

Gambar 6. Pomatocalpa sp. aff. Marsupiale .Echon Bieth

Buah dan Bunga : Tidak di temukan saat pengamatan

Habitat : Hidup menempel pada pohon mati sulit di identifikasi, terdapat di hutan pantai pada ketinggian $3 \mathrm{~m}$ dari permukaan tanah.

\section{Faktor - Faktor Penyebab Kepunahan Anggrek}

Berkurangnya populasi anggrek epifit di kawasan hutan Pulau mansinam disebabkan oleh beberapa faktor antara lain : adanya pengambilan yang berlebihan oleh masyarakat dari dalam maupun dari luar pulau. Hal ini di sebabkan karena dekatnya jarak Pulau Mansinam dengan kota Manokwari yang hanya tiga kilometer sehingga memudahkan orang mengunjungi pulau mansinam. Disamping itu banyak para pengunjung ke pulau ini disebabkan oleh nilai historisnya bagi umat kristiani. Semakin banyaknya para pengunjung maka pulau ini pun sudah tidak terisolasi lagi dari gangguan aktivitas manusia, termasuk pengambilan anggrek di dalam kawasan hutan mempercepat lagi laju kepunahan anggrek karena habitatnya alaminya mengalami penyempitan, dan jika berlangsung terusmenerus maka populasi anggrek epifit yang ada pada Pulau Mansinam tersebut akan berkurang bahkan menjadi punah.

Disamping faktor-faktor tersebut di atas, yang turut berperan terhadap berkurang dan hilangnya anggrek epifit pada kawasan Pulau Mansinam adalah rendahnya laju penyebaran gen dari sumber gen. Secara geografis diketahui bahwa hutan gunung meja merupakan sumber gen bagi Pulau Mansinam. Rendahnya laju migrasi gen dari sumber gen hutan Gunung meja disebabkan karena adanya pemukiman dan selat yang memisahkan kedua tempat tersebut, sehingga proses penyebaran gen oleh burung, serangga dan angin menjadi terhambat.

\section{KESIMPULAN}

Pada kawasan hutan Pulau Mansinam berhasil di jumpai 6 jenis anggrek yaitu : Dendrobium bifalce Lindl., Dendrobium mirbelianum Gaudich., Dendrobium schulleri J.J.Sm., Grammatophylum scriptum (Lindl.) Blume., Grammatophylum speciosum Blume., 
Pomatocalpa sp. Aff. marsupiale. Sementara jenis-jenis pohon inang yang sering di tumbuhi anggrek adalah Alstonia scholaris, Mangifera indica, Ficus benyamina, Terminalia catappa, Baringtonia asicatica, Intsia bijuga, dan Pometia pinnatai.

\section{DAFTAR PUSTAKA}

Abaire T, Worabai MS. 2018. Deskripsi morfologi jenis ular dan katak pada kawasan hutan Pulau Mansinam. Jurnal Kehutanan Papuasia. 4(1): 57-64. DOI: https://doi.org/10.46703/jurnalpapuasia .Vol4.Iss1.91

Arief A. 1994. Hutan, hakekat dan pengaruhnya terhadap lingkungan. Yayasan Obor Indonesia. Jakarta

Bratawinata AA. 2001. Ekologi hutan tropis dan metode analisi hutan. Badan kerjasama perguruan Tinggi Negeri Indonesia Timur. Samarainda.
Lekitoo K, Peday HFZ, Panambe N, Cabuy RL. 2017. Ecological and ethnobotanical facet of 'Kelapa Hutan' (Pandanus spp.) and perspectives towards its existence and benefit. International Journal of Botany. 13: 103-114.

Mooy DB. 2005 Status populasi anggrek epifit di kawasan hutan Pulau Mansinam kabupaten Manokwari. [Skripsi]. Fakultas Kehutanan Universitas Negeri Papua, Manokwari.

Petocz R. G. 1987. Konservasi alam dan pembagunan di Irian Jaya.Strategi pemanfaatan sumber daya alam secara rasional. Grafitipres, Jakarta.

Soerianegara I, Indrawan S. 1976. Ekologi hutan indonesia. Fakultas Kehutanan. Bogor.

Soetopo L. 2009. Keanekaragaman dan pelestarian tanaman anggrek. Malang: Penerbit Citra. 